\title{
16
}

\section{The Influence of Disciplinary Differences on Consultations with Faculty}

\author{
Virginia S. Lee
}

University of North Carolina, Chapel Hill

In recent years researchers have begun to investigate the nature of disciplinary differences in higher education and their implications for teaching and learning. While researchers have studied several aspects of disciplinary differences, they have given comparatively little attention to the significance of these differences for faculty development. After reviewing selective, representative studies from the literature on disciplinary differences, this paper develops a general framezerk for determining how the characteristics of a discipline influence the dynamics of the consulting relationship using the example of the hard sciences. It explores what kinds of discipline-specific knowledge will be important for consultants and under what circumstances and the implications for effective consulting strategies. The paper concludes with recommendations for future research in this area.

Tn recent years researchers have begun to investigate the nature of disciIplinary differences in higher education and their implications for teaching and learning. While researchers have studied several aspects of disciplinary differences, they have given comparatively little attention to the significance of these differences for faculty development. In fact, the concepts, knowledge structures, methods of inquiry, and habits of mind learned in disciplines play a critical, mediating role in consultations. They shape fundamental assumptions about teaching and learning, influence problem representation in the classroom, and affect receptivity to, and interpretation of, pedagogical innovation. Educational consultants need a better understanding of the influence of disciplinary differences 
on their interactions with clients and the mechanisms by which that influence occurs.

After reviewing selective, representative studies from the literature on disciplinary differences, I use the example of the hard sciences to develop a general framework for determining how the characteristics of disciplines may influence the dynamics of the consulting relationship and under what circumstances these influences will be most salient. I describe certain characteristics of the sciences and the types of challenges these characteristics will pose for consultants. Subsequently, I highlight features of the consulting situation that may heighten or lessen the impact of these characteristics on the consulting relationship. The section concludes with a set of consulting strategies that may be particularly effective in working with science faculty in light of the previous discussion. In the summary section, I suggest that the framework developed with reference to the hard sciences may apply equally well in all consulting relationships regardless of the faculty member's discipline, and I recommend future areas of research in this area.

\section{REVIEW OF THE LITERATURE}

Existing research on disciplinary differences falls broadly into four areas: subject matter and knowledge structure, teaching practices, student learning, and the characteristics of departments. In his early work, Biglan (1973a) identified a model of disciplinary differences based on the distinguishing characteristics of subject matter: degree of paradigm development ("hard" or "soft"), orientation to practical application ("pure" or "applied"), and concern with life systems ("non-living" or "living"). Subsequently, Donald $(1983,1995)$, exploring the distinctive knowledge structures of disciplines, found four areas of difference: characteristics of concepts, logical structure, the processes of knowledge validation, and the validation criteria themselves. After a period when much educational research focused on certain generic teaching behaviors as the fundamental ingredients of effective teaching, Shulman $(1986,1987)$ reinstated the importance of subject matter or content knowledge in teachers' professional repertoire. Advancing the construct of pedagogical content knowledge, he claimed that teachers needed to know both "the structures of subject matter, the principles of conceptual organization, and the principles of inquiry" $(1986$, p. 9) of their discipline as well as how to transform these aspects of their disciplines to facilitate the understanding of their students. Murray and Renaud (1995) noted disciplinary differences in the 
frequency of occurrence of specific low inference teaching behaviors related to organization, pacing, interaction, rapport, and the use of mannerisms. Braxton (1995) suggested differences in teaching goals, teaching practices, and the balance of teaching and research in hard and soft disciplines, using Biglan's terminology. Kolb (1994) noted the correspondence between two of Biglan's dimensions, degree of paradigmatic development ("hard," "soft") and orientation to practical application ("pure," "applied") and the dimensions of his learning styles model-abstractnessconcreteness and reflective-active, respectively. Donald (1995) also explored the comparative challenges of different disciplines' knowledge structures on student learning. And Entwistle and Tait (1995) developed various ways of typifying student styles of learning and approaches to study: deep, surface, and strategic approaches to study; serialistic and holistic styles of learning; and differences in breadth, depth, and structure of their understandings of subject matter. While finding some disciplinary differences in student learning, they identified more general principles to guide effective teaching and learning. Finally, using his model of subject matter differences, Biglan (1973b) noted differences in various aspects of the structure and output of departments: social connectedness, productivity, types of scholarly production, and relative commitments to research, teaching, and service.

\section{Disciplinary Differences and Faculty Development}

While this literature is certainly suggestive for faculty developers, researchers need to investigate more explicitly how the characteristics of a particular discipline influence the dynamics of the consulting relationship, what discipline-specific knowledge consultants need, and under what circumstances. Certainly not all consulting situations require discipline-specific knowledge. In many cases, application of general principles of teaching and learning, imagination, and intuition may be sufficient to resolve a client's problem. But at times, discipline-specific knowledge may be helpful and even necessary:

- To enhance consultants' credibility with the client

- To diagnose the underlying problem in a consultation accurately and to identify the appropriate strategies for addressing it

- To assess faculty members' expectations of the consulting relationship properly, including how they define the teaching and learning issue and the consultant's role in resolving it 
- To understand possible areas of resistance such as prior knowledge and beliefs about teaching and learning, or how previous academic training influences how faculty assess new information

- To enhance consultants' understanding of the influence of their own academic training on their perception of teaching and learning issues

- To determine faculty members' position and status within their departments and the extent of their influence over teaching and learning processes

Research suggests subject areas for which discipline-specific knowledge may be most essential for the success of the consulting relationship. Using Biglan's model, most faculty developers should work with comparative ease in soft disciplines (e.g., English, psychology, social work) due to their own academic training in these disciplines (Graf \& Wheeler, 1996) and the nature of the client disciplines themselves. These are "affinity" disciplines (Braxton, 1995) whose teaching practices are most consistent with those associated with effective teaching and enhanced student learning. Among the soft disciplines, consultants may work with greater ease in applied-life subject areas. This is due ultimately to the fundamental object of attention of these disciplines-human beings and human processes, interaction, development, and change-and their paradigmatic and methodological flexibility. Conversely, the need for discipline-specific knowledge will be more urgent when working in the hard disciplines (e.g., chemistry, engineering, statistics), both because of their relative paradigmatic and methodological rigidity and because the majority of faculty developers lack advanced training in these areas (Graf \& Wheeler, 1996).

The following section examines specific characteristics of the hard disciplines (e.g., chemistry, physics, astronomy, biology) and their influence on the dynamics of the consulting relationship. By examining a category of consulting relationships where the influence of the discipline is clear and dramatic, I hope to illuminate features of this influence that exist in interactions with all clients but that are often subtler and thus harder to recognize.

\section{The Case of the Hard Disciplines}

\section{The Nature of the Hard Disciplines}

In his classic essay, The Structure of Scientific Revolutions (1962/1996), Thomas Kuhn portrayed the inherent conservatism of science and the overwhelming power of the prevailing paradigm in scientific inquiry in 
the following description of normal science, the type of science practiced by most scientists most of the time:

Closely examined, whether historically or in the contemporary laboratory, that enterprise seems an attempt to force nature into the preformed and relatively inflexible box that the paradigm supplies. No part of the aim of normal science is to call forth new sorts of phenomena; indeed those that will not fit the box are often not seen at all. Nor do scientists normally aim to invent new theories, and they are often intolerant of those invented by others. Instead normal-scientific research is directed to the articulation of those phenomena and theories that the paradigm supplies (p. 24).

He further describes the necessary restrictions, "born from confidence in a paradigm," that "[force] scientists to investigate some part of nature in a detail and depth that would otherwise be unimaginable" (p. 24). In periods when paradigms are well-established, fact-gathering in two formsdetermination of significant fact and matching of facts with theorycharacterizes the vast majority of scientific research.

Kuhn also discusses the influence of the dominant paradigm on the education of future scientists:

The study of paradigms is what mainly prepares the student for membership in the particular scientific community with which he will later practice. Because he there joins men who learned the bases of their field from the same concrete models, his subsequent practice will seldom evoke overt disagreement over fundamentals. Men whose research is based on shared paradigms are committed to the same rules and standards for scientific practice. That commitment and the apparent consensus it produces are prerequisites for normal science (p. 11).

In post-secondary science education, students typically first learn the dominant paradigm through textbooks, then by replicating experiments, and finally, in graduate or post-doctoral study, by conducting original, but still highly circumscribed research of the sort described above.

In other words, there is a high degree of interdependence between the characteristics of the dominant paradigm-its subject matter, knowledge structures, and methods of inquiry on the one hand-and characteristic teaching practices and qualities of student learning on the other. The 
dominant paradigm in a given field often comprises many concepts with highly technical meanings that may be represented symbolically and at a high level of abstractness. Further, concepts have a high degree of salience, leading to hierarchical knowledge structures with high concept interdependence. The understanding of subordinate concepts depends upon mastery of superordinate concepts. And as discussed above, accepted methods of inquiry in these disciplines are relatively circumscribed, restricted almost exclusively to the scientific method using quantitative analytical tools and focused on very narrow, specialized research questions.

Methods (e.g., experiment, reproducibility, the use of conflicting evidence, counterexamples) and standards (e.g., consistency, precision, accuracy) of knowledge validation are rigorous (Donald, 1995).

Given the sheer density of subject matter and the often unquestioned pedagogical assumption of paradigm mastery, teaching goals often emphasize mastery of technical subject matter, knowledge acquisition, and, in some disciplines, direct application. Curricula have a tendency to become quite rigid, and courses, most with a strong emphasis on content coverage, often highly interdependent. Because of the importance of content acquisition, most instructors employ a very restricted set of teaching practices that focus on delivery of content, primarily in the lecture mode. Effective teaching practices emphasize organization of content, appropriate pacing in the delivery of content, and clarity in its presentation. Emphasizing mastery of the dominant paradigm, assessment practices typically favor traditional in-class testing with a reliance on multiplechoice and short-answer formats that test low-level outcomes at the knowledge and comprehension levels and problem sets that test application.

The structural characteristics of departments and the organization of inquiry are additional influences on teaching practices in the hard disciplines. Given the overwhelming influence of the dominant paradigm, research frequently takes place in teams, minimizing the contribution of individual researchers. Correspondingly the individual instructor plays a far less important role than the paradigm itself and the collective effort to first master and then modify and test it. Finally, the reward structure in the hard disciplines often favors research overwhelmingly over teaching.

\section{Implications for the Educational Consultant}

The density of the dominant paradigm alone-the nature of concepts, their number, and their high interdependence-presents real challenges 
in transforming its subject matter in ways that facilitate student understanding (Shulman, 1986). In addition, the interdependence between the dominant paradigm, the organization of inquiry, and teaching practices can create formidable barriers to implementation of effective principles of teaching and learning. The resulting culture of teaching and learning in the hard disciplines will affect the frequency with which instructors in these disciplines seek the advice of consultants as well as the dynamics of the consulting relationship itself. Because the sciences have traditionally placed less emphasis on teaching per se and more emphasis on mastery of content, instructors in these fields are less likely to solicit the expertise of educational consultants. When consulting relationships are formed, the subject matter and habits of thought shaped by the dominant paradigm and their effect on teaching practices will strongly influence client expectations, the facility with which consultants will work in these fields, and ultimately, the types of consulting strategies that will be most effective. Consultants working in these fields will face several challenges:

Credibility. Traditionally, the hard-pure disciplines have held a privileged position in the hierarchy of universities by virtue of the technicality, abstractness, and symbolic representation of their concepts and the refinement and rigor of their methods of inquiry and standards of validation. As a soft-applied discipline, education occupies a substantially lower position in the hierarchy, and the disparity in status between the hard-pure and soft-applied disciplines is large. This discrepancy may influence the frequency with which instructors in the hard disciplines seek the advice of educational consultants and their degree of skepticism concerning its value. Educational consultants may have particular difficulty establishing their credibility with instructors in the hard disciplines.

The nature of the subject matter. As paradigms develop and mature, their concepts proliferate, acquire increasingly technical meanings, and become highly interdependent. As a result the field becomes more and more impenetrable to those outside the discipline. Even for those inside the discipline, decisions concerning selection and representation of content to facilitate student learning will be difficult. Unless they have advanced scientific training, consultants may have particular difficulty working in these fields. They will naturally have less confidence working in fields they themselves do not understand. Further, they may have difficulty interpreting and evaluating teaching practices that emphasize content delivery. Finally, they may simply be less interested in fields so far outside their own training. Their inability to "talk the language" may further undermine their credibility with faculty in the sciences. 
Accustomed patterns of thought and metbods of inquiry. As described above, patterns of thought and methods of inquiry in the sciences are far more circumscribed than in other academic disciplines. These habits and methods influence a number of areas: how scientists frame problems; the types of questions they ask; the kinds of evidence they will accept; the methods they will use to examine it; the types of inferences they will be willing to make; and the methods and rigor with which they accept knowledge claims in their fields, and the value they assign to them. These characteristics of scientific inquiry may affect how readily science instructors accept methodologies from other fields like education and the knowledge claims that result from them, and how willing they would be to apply the implications of these claims to their own classrooms.

Classroom practices and implied assumptions about teacbing and learning. The most common classroom practices in the sciences as described above emanate from a number of assumptions, both implicit and explicit, about teaching and learning. These include the following: instructors dispense and students receive knowledge; until students have mastered a large portion of the dominant paradigm, they are unable to engage in real scientific inquiry; in undergraduate science courses we are training future scientists who will conduct independent research in their fields; the way the field practices science and how students learn are different; and learning is mastery of content. At the same time, most of these assumptions contradict what we know about teaching practices that facilitate student learning. These assumptions are held tenaciously and are largely unexamined, making them all the more recalcitrant. Changing teaching practices without first unearthing these assumptions and bringing them to light is very difficult.

\section{Features of the Consulting Relationship}

The impact of these challenges on the relationship between consultants and instructors in these disciplines will depend upon certain features of the consulting situation:

Nature of the consulting problem. Educational consultants encounter a wide range of issues and problems as defined by their clients. Some problems may lend themselves to "quick fixes" and may require comparatively little discipline-specific knowledge (e.g., handling a difficult student), while others will be more extensive and require more knowledge (e.g., curricular design). Certain factors also determine whether the consultant chooses to define the problem differently in a manner that recognizes the need for more discipline-specific knowledge and then makes 
this known to the client. In part, a proper diagnosis of the client's problem may depend upon discipline-specific knowledge. But the consultant's options about problem-definition must be based on an assessment of the client, his or her readiness to accept alternative representations of the problem, and the consultant's ultimate investment and interest in the consulting problem. For purely pragmatic considerations (e.g., current workload), the consultant may choose to resolve a problem satisfactorily, but not optimally, using general principles of teaching and learning, intuition, and imagination, and move on to other assignments.

Likely impact of the consultant's intervention. At the outset of the consulting relationship, consultants may wish to assess the likely impact of their intervention based on factors such as the interest and motivation of the client and the instructor's status within the department. A single instructor can be a powerful change agent in a given department, depending upon his/her interest, status, and influence. If this is the case, it may be well worth a consultant's time to develop discipline-specific knowledge to help effect a deep and long-lasting impact on teaching practices in the department.

Lengtb of the consulting relationsbip. The length of a consulting relationship can vary from a single session to several years, depending upon a variety of factors. The instructor's dedication to teaching, the expertise and interest of the consultant, the personal chemistry between consultant and client, and the tangible results of consultations can all be important. As the relationship matures, discipline-specific knowledge may play an increasingly important role as the consultant gradually becomes more familiar with the field and is able to advise at deeper and deeper levels.

Client expectations and the role of the consultant. Clients enter consulting relationships with different expectations concerning the role of the consultant and the purpose of the consultation, which will in turn affect the role discipline-specific knowledge plays in the interaction. Some instructors may define the consultant's role quite narrowly in ways that touch the nature of the discipline only tangentially, while others will define the role far more comprehensively. Other clients will assume that the consultant brings expertise primarily in teaching and learning, while they themselves will supply subject matter expertise. Still another group of instructors may expect the consultant to provide both content and pedagogical expertise. Depending upon their assessment of the consulting relationship, consultants may try to alter client expectations to coincide more closely with their own. 


\section{Effective Consulting Strategies}

The culture of the discipline may also determine the most effective consultation strategies in working with clients. Given the characteristics of the hard disciplines described above, the following strategies may be particularly effective in working with instructors in the hard disciplines:

1) During the first interaction with the client, speak openly about the powerful influence discipline culture plays in our assumptions about teaching and learning, the roles instructors and students typically play, content representation, and teaching and assessment practices.

2) Support suggested revisions in classroom teaching practice and claims concerning teaching and learning with evidence from the educational research literature.

3) Ask clients about the major concepts in their fields, their interrelationships, and how the field constructs knowledge including methods of inquiry and validation criteria. The use of concept maps to represent course content and vee diagrams (Novak \& Gowin, 1984) to clarify the relationship between course content and methods of inquiry may be particularly effective consultation tools in working with clients in the hard disciplines.

4) Utilize a variety of techniques to gather empirical evidence about teaching and learning in the classroom including classroom observations, videotaping, peer and student evaluations, student assessment results, and small group instructional diagnoses (SGIDs).

5) Apply a consulting model that mimics the research process itself. By using a classroom research approach, the consultant may assist the client in defining a teaching and learning problem arising in the classroom, gather relevant data to investigate it, analyze the data, and, based on the analysis, decide upon an appropriate revision of classroom practice (Nyquist \& Wulff, 1988). Similarly classroom assessment techniques, designed by instructors to obtain localized evidence of learning, provide an empirical basis for evaluating the effectiveness of teaching and may appeal to instructors in the hard disciplines (Angelo \& Cross, 1993).

6) Identify key individuals in the hard disciplines who have an interest and commitment to teaching, and work with and support them intensively. Grounded both in the language and logic of the dominant paradigm as well as principles of effective teaching and learning, such individuals may have greater credibility than educational consultants themselves and become highly effective change agents within their disciplines. 


\section{SUMMARY}

The specific characteristics of a discipline-the nature of the subject matter and its knowledge structure, methods of inquiry, typical teaching practices, the quality of student learning, and the structure of departments-all influence the dynamics of the consulting relationship. The previous discussion utilized the robust case of the hard disciplines to illuminate the mechanisms of this influence as well as the role played by certain parameters of the consulting situation (e.g., nature of the problem, likely impact, length, client expectations, consultant role). However, this framework should be helpful in assessing the influence of disciplinary differences in consultations with instructors from any discipline area. It also suggests a number of areas for future research, including more rigorous, empirical examination of selected features of the framework itself; the effectiveness of specific consulting strategies in dissipating faculty resistance in different disciplines; the relationship between the knowledge structure of a particular discipline and its teaching practices; and the influence on the consulting relationship of differences in academic training between consultants and faculty members.

\section{REFERENCES}

Angelo, T. A., \& Cross, K. P. (1993). Classroom assessment techniques: $A$ bandbook for college leachers (2nd ed.). San Francisco, CA: Jossey-Bass.

Biglan, A. (1973a). The characteristics of subject matter in different academic areas. Joumal of Applied Psychology, 57, 195-203.

Biglan, A. (1973b). Relationships between subject matter characteristics and the structure and output of university departments. Joumal of Applied Psychology, $57,204-213$.

Braxton, J. M. (1995). Disciplines with an affinity for the improvement of undergraduate education. In N. Hativa \& M. Marincovich (Eds.), Disciplinary differences in teaching and learning: Implications for practice (pp. 7-17). San Francisco, CA: Jossey-Bass.

Donald, J. G. (1983). Knowledge structures: Methods for exploring course content. Journal of Higher Education, 54(1), 31-41.

Donald, J. G. (1995). Disciplinary differences in knowledge validation. In N. Hativa \& M. Marincovich (Eds.), Disciplinary differences in teaching and learning: Implications for practice (pp. 7-17). San Francisco, CA: Jossey-Bass.

Entwistle, N., \& Tait, H. (1995). Approaches to studying and perceptions of the learning environment across disciplines. In N. Hativa \& M. Marincovich 
(Eds.), Disciplinary differences in teaching and learning: Implications for practice (pp. 93-104). San Francisco, CA: Jossey-Bass.

Graf, D., \& Wheeler, D. (1996). Defining the field: The POD membership survey. Valdosta, GA: POD Network.

Kolb, D. A. (1994). Learning styles and disciplinary differences. In K. A. Feldman \& M. B. Paulsen (Eds.), Teaching and learning in the college classroom (pp. 151-164). Needham Heights, MA: Ginn Press.

Kuhn, T. (1996). The structure of scientific revolutions (3rd ed.). Chicago, IL: University of Chicago Press. (Original work published 1962.)

Murray, H. G., \& Renaud, R. D. (1995). Disciplinary differences in classroom teaching behaviors. In N. Hativa \& M. Marincovich (Eds.), Disciplinary differences in teaching and learning: Implications for practice (pp. 31-40). San Francisco, CA: Jossey-Bass.

Novak, J. D., \& Gowin, D. B. (1984). Learning how to learn. Cambridge, UK: Cambridge University Press.

Nyquist, J. D., \& Wulff, D. H. (1988). Consultation using a research perspective. In Lewis, K. G. (Ed.), Face to face: $A$ sourcebook of individual consultation techniques for faculty/instructional developers (pp. 33-50). Stillwater, OK: New Forums Press.

Shulman, L. S. (1986). Those who understand: Knowledge growth in teaching. Educational Researcher, 15, 4-14.

Shulman, L. S. (1987). Knowledge and teaching: Foundations of the new reform. Harvard Educational Review, 57(1), 1-22.

Contact:

Virginia Lee

Center for Teaching and Learning

University of North Carolina, Chapel Hill

CB \#3470, 316 Wilson Library

Chapel Hill, NC 27599-3470

(919) $966-1289$

(919) 962-5236 (FAX)

vslee@email.unc.edu

Virginia Lee has been the Director of Teaching Assistant Development and a consultant at UNC-Chapel Hill's Center for Teaching and Learning since 1995. She is also a Clinical Assistant Professor in the University's School of Education. A relative newcomer to the academy, she has over 20 years of professional and 
administrative experience in corporate, non-profit, and academic settings. She earned an MBA with a concentration in organizational management and strategic planning in 1982 and a Ph.D. in educational psychology in 1995. She has published articles on postsecondary teaching and learning and has presented nationally on a variety of topics. 